\title{
Combining Software Agents and Gaming through Student Play, an Educational Module in Agent SocialMetric
}

\author{
Antonieta Kuz, Mariana Falco \\ Grupo de Investigación y Desarrollo Aplicado a Sistemas \\ Informáticos (GIDAS), UTN-FRLP \\ La Plata,Buenos Aires, Argentina \\ \{akuz,mfalco\}@frlp.utn.edu.ar
}

\author{
Roxana Silvia Giandini \\ LIFIA (UNLP), CIC \\ La Plata, Buenos Aires, Argentina \\ giandini@lifia.info.unlp.edu.ar
}

\begin{abstract}
We are in a time where trends and ICTs are capable of leading important educational changes and allowing an advance in flexible teaching environments, through innovation and collaboration between educational institutions. Teachers have a large number of technologies to use as an ally in the classroom, such as software agents in the teaching-learning process. The objective of this article is to make known the educational module Student Play that allows to establish interactive games with students to educate in values through conversational agents, and that is embedded in a web tool called Agent SocialMetric.
\end{abstract}

Keywords-Agent SocialMetric; Software Agents; Educational Software; Games; Student Play.

\section{INTRODUCTION}

ICTs led to a process of global connectivity that allowed the generation and socialization of the information and the knowledge, eliminating the space-time barriers [1] and allowing them to become pillars for technological innovation and economic growth. The list of technologies available for use in the teaching-learning process is progressively updated [2], which allow the teacher to obtain a true digital ecosystem for use but ICTs must be considered as those capable of generating new learning scenarios where instead of using teacher-centered ICTs [3], they are used in student-centered models (remembering that the students are the New Millennium Learners) and connectivity. In the digital world and in the knowledge society, the ability to memorize data is no longer enough, but it is essential to have the capacity to provide solutions to problems with creativity and innovation, knowing how to move in the uncertain and dynamic future.

Technology Enhanced Learning (TEL) is a complex field within which an important point is educational software, and it allows to understand how learning mechanisms may be enhanced by technology, how educational practices changed or how to design adapted educational software to a particular pedagogical setting. Educational software is a means to implement computer-based pedagogical settings and thus contribute to the achievement of pedagogical objectives [4]. The demand for educational software is growing exponentially with the surge of interest in educational reform, the Internet, and distance learning.
A large number of researchers [5], [6] have emphasized the importance of clear leadership [7] in order to develop positive attitudes of teachers towards the use of ICTs, facilitating innovative ways of using them in education. Thus, ICTs have covered and related fields previously unrelated to education, such as gaming, virtual reality, neuroscience, agile methodologies and artificial intelligence (AI). The area of AI allowed the development of Intelligent Tutoring Systems (ITS) as well as Learning Companion Systems (LCS), through pedagogical software agents (e.g. [8], [9], [10], [11], [12]).

Another field lies in the culture of games because it has become a trend for educational usage as a useful training and motivation tool [13]. Games in general are considered as an activity of the person, which varies according to each context. As tablets and smartphones have been optimized, computers and gaming consoles are no longer the only way to interact with other players online, making the game a portable activity that occurs in different settings. The creativity that is activated and put into operation when playing, awakens the impulse that is necessary to recreate the reality and transform it. And while games are not exclusive to children, they constitute an irreplaceable motor of their development. Therefore, the combination of the most effective principles of learning mediated by technology and multimedia design will provide methodologies and tools that will favor student learning.

Agent SocialMetric [14] provides a methodology based on the integration of Social Network Analysis (SNA) and the development of an interface software agent, called Albert, that assist teachers in the classroom environment. Considering the advances in educational trends, the aim of the present article is not only to present the tool but also to display the new module called Student Play, which establish interactive games with preschooler students and, thus, promoting an environment that facilitates education in values through various software agents. Education in values allows us to discern what children need to live and interact with others, so that friendship, understanding, perseverance, tolerance, generosity, honesty, solidarity, respect for diversity, empathy, collaboration, courage, among others; are essential for a healthy development of them. The article is structured as follows: section 2 discussed the state of art of ICTs in Education. Section 3 describes the related work, while section 4 directly addresses the Agent SocialMetric tool, 
describing its motivation and introducing the Student Play module immersed in values education. Finally, section 5 presents the conclusions and future work.

\section{STATE OF ART}

From its beginnings, the educational system has emerged with the development of reading, writing and mathematics [15]. In those times, educators have had to understand and decide what content was feasible to include in the student's curriculum, identifying the best pedagogical and methodological practices for successful learning. Over time, these activities have been affected mostly by improvements in knowledge [16] and the advancement of society and technologies. From the outset, ICTs were incorporated as a modern instrument that allowed teachers to innovate and caught the attention of their students [17] through the incorporation of new objects and tools into the class, only considering them as isolated and independent elements rather than integrated into the curriculum [3]. But the accelerated growth in the use of ICTs [7] has been followed "by the recognition of the potential for such technology to transform the classroom environment" [18].

Over 20 years ago Davis, Borgatti and Warshaw [19] developed a theory that made possible to investigate the reasons why people use technologies such as computers and their attitude towards them. Through the testing of the Technology Acceptance Model (TAM) it was possible to determine that people's use of technology could be predictable by their intentions and that perceived usefulness (a concept derived from TAM) was strongly related to them. In the model, the external variables, such as school policies on using ICTs, represent the influences on teachers which come from outside their sphere of control. Several studies have identified a wide range of skills and competencies which teachers felt they needed in order to find ICTs easy to use. Therefore, the positive factors included the confidence in using ICTs and the ease to think of new lesson ideas while the negative factors covered the need for more technical support and the insufficient access to the resources, among others [20].

If teachers do not visualize the need to change the way they structure their classes it is very likely that they will not use ICTs, but if they see them as useful to the process then their attitude towards them will be positive [7]. A large number of researchers [21], [22], [23], [24] have emphasized the importance of user attitudes in the use of ICTs, since their satisfaction will address the successful implementation of technologies in educational practice. According to Polancic et al. [25], "a key assumption of TAM is that external variables influence the decision to use particular IT only indirectly through their impact on users' beliefs". In TAM, perceived usefulness embodies the role of user beliefs indicator as it provides information on how users successfully experience the implementation of computers and computer systems [26].

At the present time it is fundamental to recognize, on the one hand, that the teacher has a large number of technologies that allow him/her to carry out not only the teaching process but also some educational management; and on the other hand, that technologies are increasingly varied, and allow embrace and obtain feedback from different areas of knowledge (such as neuroscience [27]) in a thoughtless beginning to relate to the teaching-learning process. The emerging technologies mark fluctuations in global trends and 21st century skills [6] such as internet of things, learning analytics, augmented reality, games, social networks, big data, and machine learning [2], [28].

\section{RELATED WORK}

Around 1960 arose the development of technology for conversational agents, where Eliza was the first conversational agent developed by Joseph Weizenbaum. These agents are also known as chatterbot or chatbot, originally coined by $M$. Mauldin in 1994. A conversational agent is an artificial living entity designed to have conversations with real humans [29] and chatbots can be found on screens, virtual worlds, but also in the real world through projections e.g. holographic projections or physically speaking and responding [30]. The conversational agents provide a natural language interface to users and the main benefit lies in the simplicity of the management of the dialogue along with the development of the database.

One of the most known and powerful chatbots (but still unable to pass the Turing Test) is A.L.I.C.E, and as the design of these chatbots became more sophisticated, the objectives for which they were created were expand-ed. Thus, they have been used as private tutors, to determine personality, to simulate chats with humor, among others. A pedagogical agent makes decisions about how to maximize a student's learning and environment to meet their goals [31] and promote collaborative learning. From the functional point of view, agents can occupy different roles because they can serve different purposes. Therefore, pedagogical agents can develop in two fundamental roles as Intelligent Tutoring Systems (ITS) as well as Learning Companion Systems (LCS).

According to Chan [32], the ITS are modeled on the idea associated with private tutors and provide individualized instruction which enhances the personalized attention of students. The ITS were conceived as a model with two agents, implanting the figure of a computer simulated teacher, a vision that remains strong today [33]. However, the LCS embodies a model with three agents where the computer simulates two independent agents (a tutor and a learning companion) coexisting, and a third one which enriches the social context. The learning companion may act as a collaborator or as a competitor to the student (e.g. [34], [35], [36], [37]).

In the last few years, there has been several applications surrounding the gamification i.e. "the notion that gaming mechanics can be applied to routine activities" [13] because the ways in which people learn have been changing and expanding as interactive content available via the web such as Sicko' ${ }^{1}$. A large number of studies have been carried out to investigate and examine motivation in video games; some of them associated the causes to the narrative context [38], [39], [40], while others found that motivation is related to goals and rewards [41], [42]. Nevertheless, they all concluded that the

\footnotetext{
${ }^{1}$ SICKO, (accessed 02.04. 17).

http://med.stanford.edu/sm/archive/sicko/game/SICKOTitle.html
} 
motivation to play is a key topic in educational video games, regardless the causes.

Considering that games and videos are two of the primarily ways that students learn outside schooling, the game-like environments transform assignments into exciting challenges and develop inductive reasoning skills. As Gros said [43], "digital games are user-centered; they can promote challenges, co-operation, engagement, and the development of problemsolving strategies". As for any education-oriented approach [44], "instructional technology only works for some kids, with some topics, and under some conditions - but that is true of all pedagogy. There is nothing that works for every purpose, for every learner, and all the time" [45].

Games allow students to spend hours learning on their own time [46], and there are several educational games that require the use of logic, memory, problem-solving, critical thinking skills, visualization, and discovery such as Immune Attack [47], Food Force [48], Discover Babylon [49], Quest Atlantis [50], Environmental Detectives [51] and various games designed to help develop the preschooler's math, painting and reading skills using NickJr characters.

According to Deshpande and Huang [52], "a simulation game is a game, which has elements like score, performance rating, conflict, and payoff, and simulates a real world situation for decision-making or alternative evaluation. These multisensory experiential learning tools allow the player to experience cooperation and teamwork without the risk of expensive mistakes. Simulation games follow the widely accepted "learning by doing" philosophy. Simulation gamebased learning is an extension of the problem-based learning paradigm, having all its inherent characteristics plus some additional advantages". Simulation games have been applied in several education domains such as architecture [53], business ethics [54], child development [55], interviewing skills [56], and medical [57], [58].

\section{AgENT SOCIALMETRIC}

Agent SocialMetric is an educational software tool whose primary objective is to assist teachers, simplify-ing the analysis of the social climate dynamics and the structure within [59]. The structural dimension refers to the classroom structure i.e. organization of student roles within the class while the affective dimension are things as satisfaction and friction in the class [60].

Fig. 1. Agent SocialMetric Model.

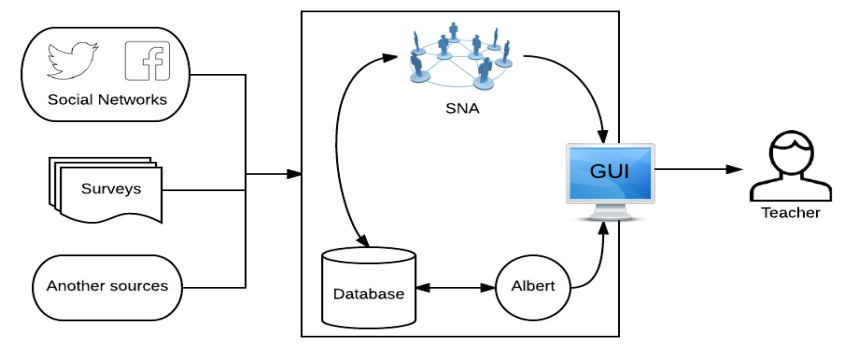

The tool, shown in Fig. 1, was developed as a didactic support in order to strengthen and manage the classroom atmosphere [14], for which two techniques were combined: SNA [61] and Conversational Software Agents [29]. SNA has been developed as a tool for measuring and analyzing the social structures that emerge from the relationships (ties or bonds) between social actors (nodes). The behavior of the group is not explained by the action of each of its components but by the set of interactions that occur between the elements in the analyzed context, therefore mapping and managing the learning process through graphs will allow to un-derstand the dynamics of the classroom.

Fig. 2. The agent called Albert.

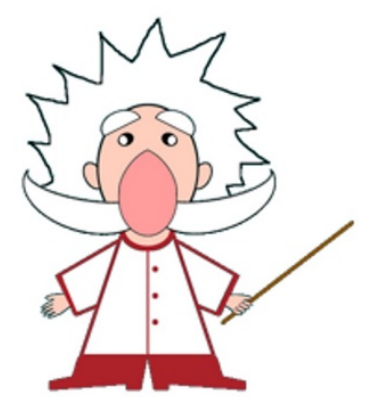

In Agent SocialMetric, Albert (see Fig. 2) [62] has been integrated through the maintenance of a conversation with the teacher, being able to fulfill two fundamental objectives. The first one is the interaction and comprehension of the questions formulated by the teacher, distinguishing from those that present a general character, from the ones referred to the classroom, given by the interpersonal relationships existing in the classroom. The second is the elaboration of an adequate response in line with what the teacher consulted, being able to solve their doubts about the classroom climate and the internal social structure of the group of students. Consequently, Agent SocialMetric is a system that should be used to answer queries automatically and immediately to teachers.

The teacher was freed from the rigid and static interfaces, so it was decided to design an avatar with the appearance of a scientist, the agent was called Albert, which can be perceived as an interface aid to the accomplishment of the tasks, regardless of whether it allows the interaction or simply is limited to giving advice. The tool has three access roles: administrator, student and teacher, and only the teacher is in charge of working with Albert. At first the system was devised for the student to be logged and only be able to answer the set of questions from the sociometric questionnaire. Trying to expand the development and increase the performance of the system, and expanding the universe of users that interact with the agents, we have devel-oped the Student Play module that will be described in the following section [63].

Games have been used in educational endeavors and there are several theoretical remarks about games and learning. For example, Rieber [64] has argued that digital games assist pupils in productive play and learning through building microworlds and playing games. Prensky [65] went further to state that developing educational games is a moral imperative because 
millennials are slow to respond to traditional Socratic methods. Following this line, Agent SocialMetric tool has been expanded with the Student Play module which is in charge of establishing with the preschoolers interactive games to educate in values, through various conversational software agents, shown in Fig. 3.

Fig. 3. Student Play module.

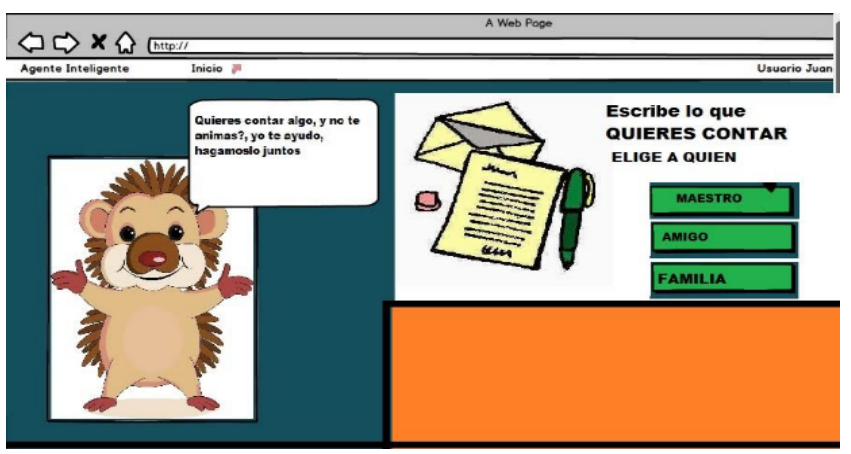

\section{A. Games to Educate in Values}

The school system is involved in children's socialization, and thus in the creation of the future society. According to Powney et al. [66], "values refer to aspects of how our lives are sustained, organized and experienced, and values may engage our cognition, emotions and behavior". Also, "values are more than simply beliefs", therefore it is extremely important that students maintain the ability to learn and to do well: to assimilate subjects, apply knowledge and master the skills that the world requires, i.e. is fundamental to promote the establishment and growth in positive habits and human values ensuring their formation as citizens. There are concerns regarding how students are acquiring and consolidating this type of training so valuable for their personal life and for the construction of a better society. From there, arises the need to have a practical tool for teachers and families, which will allow to define, observe and evaluate the development of these human values and positive habits in students [67].

Fig. 4. Category of games raised in Student Play.

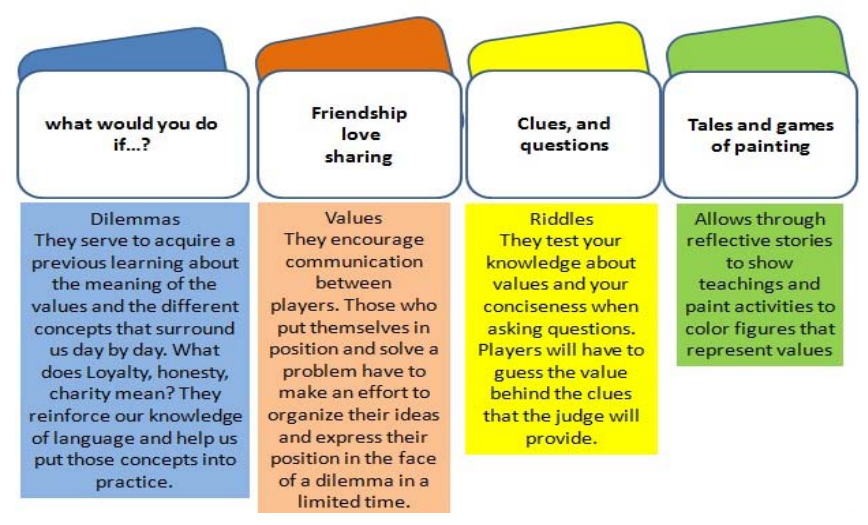

Lowering the barrier between education and real entertainment incarnates an important challenge in order to better exploit the potential of computers that is traditionally averse to learning. Achieving this goal is not only a matter of content, since simply educational content risks being perceived as boring. Hence it is feasible to mention that the game developed should feature mechanisms for acquiring knowledge and skill that are smoothly embedded in a meaningful, homogeneous, and compelling whole. The games embedded in the module (shown in Figs. 4 and 5) are aimed for children in preschool age, while proposing ethical dilemmas that playersstudents should solve using their own scale of values, empower emotional intelligence.

The tool consists on a set of indicators based on four types of habits and values [68] that facilitate coexistence and school life, work and study, personal and familial well-being, and the commitment to the people and society. They are articulated through a system of rubrics that describe the different levels of development of each aspect included in the indicator. Each one of them is composed of a statement of the aspect, a conceptual definition or approach, and the sequencing of the achievement related to that aspect. For the latter a five-level scale is used which are called minimum, low, medium, medium-high and high-optimal levels.

Fig. 5. Example of a game within Student Play.

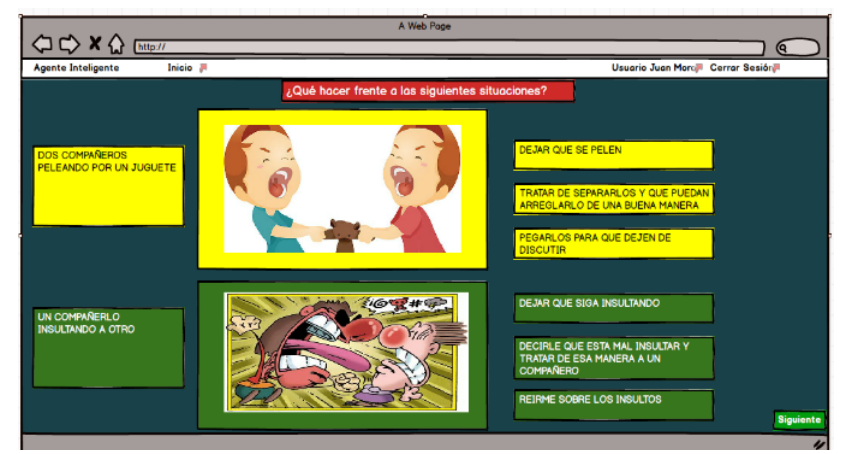

\section{B. Conversational Software Agent for Preschoolers}

The use of games and software agents can enhance learning [69], where on the one hand, games improves new strategies and the child is no longer just a subject moldable by education, but a subject that from its typical forms of expression can participate in building their own knowledge; and on the other hand, software agents try to change this relationship by assigning an animated personification known as an avatar (seen with Albert), which can establish a natural dialogue with the preschooler by giving more realism to communication and expressiveness, and facilitates the management of technology [70]. By means of Student Play, the student, once logged in, will be able to select the avatar that it will become his/her companion during the interaction and participation in the different games. Max, Rodolfo and Javier are three different personifications (shown in Fig. 6), each of them can interact with the users and have conversations expressed via text through a dialog system with the user. 
Fig. 6. Max, Rodolfo, and Javier, the avatars

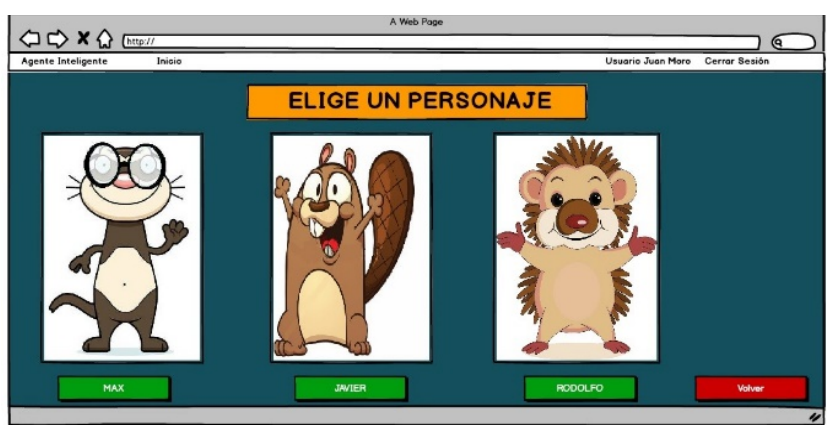

The current trend of this technology is oriented to develop systems for restricted application domains, which allow to use information about the possible words, types of phrases and intentions of the users. The characteristics that the dialogue system must have in order to be "user friendly" and effective for users are [71]: to have speech recognition, to extract semantic information from sentences, to manage dialogue, to generate answers, and to have a knowledge base. Knowledge bases arise from AI research in response to the needs that the applications of this discipline posed [72]. Therefore these bases must handle different levels of knowledge and must have a structure organized by contexts that can be defined for a particular topic or general.

Regarding the module, Agent SocialMetric already had a dialogue system for Albert so it was only necessary to recreate the knowledge base of new agents since they must be limited to the type of user who are working (preschoolers). The agents have been developed using technology that includes AIML files, intended to be stimulus-response modules which allows the bots to maintain an asynchronous communication with the server in the background. Therefore it is possible to make changes to the web page without having to reload it, which implies a substantial improvement in interactivity, speed, and ease of use.

\section{CONCLUSIONS}

The digital era in which society is immersed has led to an attempt to understand and characterize the generations of young people who were born in that era. Different studies have called it the "net generation", "generation gamer", "homo zappiens" and "New Millennium Learners" (NML). F. Pedró [73] defines the NML as one that is adept at the computer, creative with technology, and is accustomed to multitasking. Consequently the teachers, named by Prensky [74] as digital immigrants must, on the one hand, encourage creativity in the classroom, achieving dynamism and motivation; and, on the other hand, training in technological didactics, thus making possible the creation of new and diverse conceptions in the teaching-learning process.

New and more effective technologies will continue to emerge and develop, which will envisage their possible use in education. While it is clear that it is the application of various ICTs are the most important determinants of the effectiveness of such tools in education, the choices of tools are quite varied and each has its own advantages and disadvantages. New developments and advances have led to the incorporation of the actors in different fields of application as education such as the development of intelligent agent technologies bodes well for computer-based educational systems.

Pedagogical agents are animated characters designed to operate in educational settings for supporting and facilitating learning. Consequently, an educational software called Agent SocialMetric has been developed which contains Albert, a friendly agent who assist the teacher in the knowledge of the classroom climate. The aim of the tool is to become the means that allows the teacher to anticipate how to act in the classroom to foresee their behavior towards students and thus improve pedagogical strategies while strengthening the bases in the inter-action between the students and in the possible foci of conflicts, aggressions, disruptive behaviors, violence, bullying, among others.

According to UNESCO [75], "meet the needs of education systems affected by conflict, natural calamities and instability and conduct educational programmes in ways that promote mutual understanding, peace and tolerance, and that help to prevent violence and conflict. Schools should be respected and protected as sanctuaries and zones of peace. Education should promote not only skills such as the prevention and peaceful resolution of conflict but also social and ethical values". Therefore, Student Play is focused on the different research techniques that it can be used to evaluate the transformation in the attitudes and values of our students through our intervention program, seeking to prevent conflicts upholding the student's role.

Computers offer incredible opportunities for advancement in student education, from the kindergarten to higher education. It is propitious for teachers to improve their attitude towards ICTs in order to stop them from being used as elements added to the classroom, which are attractive to students, but also it is time to incorporate the notion of ICTs in student-centered models (which are actually useful to foster the teachinglearning process in NMLs). Although, there are several reasons to consider the use of educational software as positive, gent SocialMetric and Student Play are designed to contribute to the knowledge of structural patterns to detect problems of social maladjustment and fostering educational values which are long-term norms that help a person determine how they should approach a situation or interact with a person, making them an important component not only for socializing in the classroom but also for adult life. Providing education about values at an early age can ensure that they are guided by these principles throughout life. As a future work, the development of the module will be completed by setting up with different test cases in real environments.

\section{REFERENCES}

[1] M. R. Yáñez, P. Villatoro. Las nuevas tecnologías de la información y de la comunicación (TIC) y la institucionalidad social: hacia una gestión basada en al conocimiento. Vol. 108. United Nations Publications, Chile, 2005 
[2] S. Adams Becker, M. Cummins, A. Davis, A. Freeman, C. Hall Giesinger, V. Ananthanarayanan (2017). NMC Horizon Report: 2017 Higher Education Edition. Austin, Texas: The New Media Consortium.

[3] J. Cabero Almenara, "Educational consideration about information and communication technologies (ICT)”. CEF, núm. 1, mayo-agosto 2015, págs. 19-27.

[4] P. Tchounikine, Computer Science and Educational Software Design: A Resource for Multidisciplinary Work in Technology Enhanced Learning, Berlín; Springer Science \& Business Media, 2011.

[5] S. Dexter, Leadership for IT in schools. In J. Voogt, G. Knezek (Eds.), International handbook of information technology in primary and secondary education, New York: Springer, pp. 543 - 554, 2008.

[6] N. Law, Curriculum and staff development for ICT in Education. In T. Plomp, R. E. Anderson, N. Law, \& A. Quale (Eds.), Cross-national information and communication technology. Policies and practices in education. Charlotte, North Carolina: IEA, 2009.

[7] O. E. Hatlevik and H. C. Arnseth, "ICT, teaching and leadership: How do teachers experience the importance of ICT-supportive school leaders", Nordic Journal of Digital Literacy, 7(1), 55-69, 2012.

[8] N. T. Heffernan, R.K. Kenneth and L. Razzaq. "Expanding the modeltracing architecture: A 3rd generation intelligent tutor for Algebra symbolization", International Journal of Artificial Intelligence in Education 18.2 (2008): 153-178.

[9] O. Popescu, V. Aleven and K. Koedinger. "Understanding students' explanations in geometry tutoring." Proceedings of the 20th International conference on Computational Linguistics. Association for Computational Linguistics, 2004.

[10] S. Oliveras, Implementació d'un agent intelligent d'interfície per assistir a l'estudiant quan realitza feines d'aprenentatge en la plataforma telemàtica educativa del PLAN-G, Undergraduate Systems, Engineering Project, Escola Politècnica Superior. Universitat de Girona, España, 2000

[11] K. Vanlehn, C. Lynch, K. Schulze, J. A. Shapiro, R. Shelby, L. Taylor, T. Linwood, D. Treacy, A. Weinstein and M. Wintersgill, "The Andes physics tutoring system: Lessons learned", International Journal of Artificial Intelligence in Education, 15(3), 147-204, 2005.

[12] A. Kerly, E. Richard and S. Bull. "CALMsystem: a conversational agent for learner modelling." Knowledge-Based Systems 21.3 (2008): 238 246

[13] L. Johnson, S. Adams Becker, V. Estrada, A. Freeman (2014). NMC Horizon Report: 2014 Higher Education Edition. Austin, Texas: The New Media Consortium.

[14] A. Kuz, M. Falco, L. Nahuel, and R. S. Giandini. "Agent SocialMetric: Una Aplicación Práctica de Solución TIC como Soporte a la Enseñanza." In Quinta Conferencia de Directores de Tecnología de Información, TICAL 2015. Gestión de las TICs para la Investigación y la Colaboración, vol. 6. 2015.

[15] T. Divitt, D. Schulte, D. Tenenbaum (n.d.). The Write Stuff. Accessed 02/04/17: http://whyfiles.org/079writing/

[16] D.G. Moursund, Introduction to information and communication technology in education, 2005.

[17] A. Valasidou and D. Bousiou-Makridou. "The Impact Of ICTs In Education: The Case Of University Of Macedonia Students." Journal of Business Case Studies (JBCS) 4.3 (2011): 29-34

[18] J. Ainley, L. Enger, D. Searle (2008). Students in a digital age: Implications of ICT for teaching and learning. In J. Voogt \& G. Knezek (Eds.), International handbook of information technology in primary and secondary education (pp. 63 - 80). New York: Springer.

[19] F.D. Davis, R.P Bagozzi and P.R. Warshaw, "User acceptance of computer technology: a comparison of two theoretical models". Management Science. Vol 35(8). 982-1003, 1989.

[20] M. Cox, C. Preston and K. Cox, "What Factors Support or Prevent Teachers from Using ICT in their Classrooms?", British Educational Research Association Annual Conference, University of Sussex at Brighton, September 2-5, 1999.

[21] D.F. Larcker and V.P. Lessig, (1980). "Perceived usefulness of information: A psychometric examination", Decision Science 11, 1980, 121-134.
[22] G. Knezek, R. Christensen, (2008). IT competencies and attitudes. In J. Voogt \& G. Knezek (Eds.), International handbook of information technology in primary and secondary education (pp. 319-331). New York: Springer.

[23] Ø. Sørebø, H. Halvari, V.F. Gulli and R. Kristiansen. "The role of selfdetermination theory in explaining teachers' motivation to continue to use e-learning technology", Computers \& Education, 53, 1177-1187, 2009.

[24] M. Hammond, S. Crosson, E. Frakouli, J. Ingram, P. Johnston-Wilder, S. Johnston-Wilder, Y. Kingston, M. Pope and D. Wray, "Why do some student teachers make good use of ICT? An exploratory case study", Technology, Pedagogy and Education, 18, 59-73, 2009.

[25] G. Polancic, M. Hericko and I. Rozman, "An empirical examination of application frameworks success based on technology acceptance model", Journal of systems and software, 83 (4), 574-584, 2010.

[26] T. Teo, C.B. Lee, C.S. Chai and S.L. Wong, "Assessing the intention to use technology among pre-service teachers in Singapore and Malaysia: A multigroup invariance analysis of the Technology Acceptance Model (TAM)", Computers \& Education, 53, 1000 - 1009, 2009.

[27] M. Falco and A. Kuz, "Comprendiendo el Aprendizaje a través de las Neurociencias, con el entrelazado de las TICs en Educación", Revista Iberoamericana de Tecnología en Educación y Educación en Tecnología (TE\&ET), nro 17, Junio 2016, pág. 43-51

[28] M. Sharples et al., Innovating pedagogy 2014. Exploring new forms of teaching, learning and assessment, to guide educators and policy makers, Milton Keynes, The Open University.

[29] D. Perez-Marin, I. Pascual-Nieto. Conversational Agents and Natural Language Interaction: Techniques and Effective Practices. Premier reference source. Information Science Reference, 2011.

[30] D. Allison. "Chatbots in the Library: is it time?", Library Hi Tech, 30(1):95-107, 2012

[31] C. González. "Sistemas Inteligentes en la Educación: Una revisión de las líneas de investigación actuales", Revista Electrónica de Investigación y Evaluación, 10(1), 2004.

[32] T-W. Chan, "Learning companion systems." In C. Frasson. 1990.

[33] W.J. Clancey (1986). Qualitative student models. In Traub, J. F. (Ed.), Annual Reviews of Computer Science, Vol. 1, pp. 381-450. Palo Alto, CA: Annual Reviews, Inc.

[34] P. Petry and M. Rosatelli. "AlgoLC: a learning companion system for teaching and learning algorithms." Intelligent Tutoring Systems. Springer Berlin/Heidelberg, 2006

[35] R.A. Faraco, M. C. Rosatelli, F. AO Gauthier. "Adaptivity in a learning companion system." Advanced Learning Technologies, 2004. Proceedings IEEE International Conference on. IEEE, 2004.

[36] A. Baylor, "MIMIC: Multiple Intelligent Mentors Instructing Collaboratively: An Intelligent Agent-based Learning Environment for Learning Instructional Design." Third International Cognitive Technology Conference, CT. Vol. 99. 1999.

[37] A. Kerry, R. Ellis, S. Bull. "Conversational agents in E-Learning." Applications and Innovations in Intelligent Systems XVI. Springer London, 2009. 169-182.

[38] A. Waraich, "Using narrative as a motivating device to teach binary arithmetic and logic gates", Proc. 9th annual SIGCSE Conference on Innovation and Technology in Computer Science Education, Leeds, United Kingdom, 2004.

[39] S.M. Fisch, "Making educational computer games "educational"', Proc. Conference on Interaction design and children, Boulder, CO, 2005.

[40] M. D. Dickey, ""Ninja Looting" for instructional design: The design challenges of creating a game-based learning environment", Proc. ACM SI GGRAPH ‘06 conference, Boston, 2006.

[41] M. Jennings, "Best practices in corporate training and the role of aesthetics: Interviews with eight experts", Proc. at the ACM SIGCPR 01 Conference on Computer Personnel Research, San Diego, CA, 2001.

[42] G. Denis, and P. Jouvelot, "Motivation-driven educational game design: applying best practices to music education", Proc. ACM SIGCHI '05 International Conference on Advances in computer entertainment technology, Valencia, Spain, 2005. 
[43] B. Gros, "Digital games in education: The design of games-based learning environments." Journal of research on technology in education 40.1 (2007): 23-38.

[44] K. Becker, "Digital game-based learning once removed: Teaching teachers". British Journal of Educational Technology, 38, pp: 478-488, 2007, doi:10.1111/j.1467-8535.2007.00711.x.

[45] D. Mann, Documenting the effects of instructional technology, a flyover of policy questions. In W. F. Heineke \& L. Blasi (Eds), Research methods for educational technology; methods of evaluating educational technology, Vol. 1, pp. 239-249, Greenwich, CT: Information Age Pub, 2001.

[46] L.A. Annetta, "Video games in education: Why they should be used and how they are being used." Theory into practice 47.3 (2008): 229-239.

[47] K. Henry, K. Howell, E. Glinert, L. Holding, C. Swain, A. Burrowbridge, and M. Roper. "How to build serious games." Communications of the ACM 50, no. 7, pp. 44-49, 2007.

[48] Force Food. "The First Humanitarian Video Gsame." United Nations World Food Programme (2005).

[49] M. Lucey-Roper, "Discover Babylon: Creating A Vivid User Experience By Exploiting Features Of Video Games And Uniting Museum And Library Collections", in J. Trant and D. Bearman (eds.). Museums and the Web 2006: Proceedings, Toronto: Archives \& Museum Informatics, published March $1, \quad 2006 \quad$ at http://www.archimuse.com/mw2006/papers/lucey-roper/luceyroper.html.

[50] S. Barab, M. Thomas, T. Dodge, R. Carteaux, and H. Tuzun, "Making learning fun: Quest Atlantis, a game without guns", Educational technology research and development, 53(1), pp.86-107, 2005.

[51] E. Klopfer, and K. Squire. "Environmental Detectives - the development of an augmented reality platform for environmental simulations", Educational Technology Research and Development 56, no. 2, pp. 203228, 2008.

[52] A.A. Deshpande, and S.H. Huang, "Simulation games in engineering education: A state-of-the-art review", Computer Applications in Engineering Education, 19(3), pp.399-410, 2011.

[53] A. Agapiou, "The use and evaluation of a simulation game to teach professional practice skills to undergraduate architecture students", J Educ Built Environ 1, 314, 2006.

[54] P. L. Schumann, P. H. Anderson, and T. W. Scott, "Using computerbased simulation exercises to teach business ethics", Teaching business ethics, Vol. 1, Springer, Netherlands, 1997.

[55] G. F. Harper, "A simulation technique to teach a graduate course in early childhood development", Teaching Psychol 7, 218-221, 1980.

[56] K. M. Rickard and R. W. Titley, "The hypothesis-testing game: A training tool for the graduate interviewing skills course", Teaching Psychol 15, pp. 39-41, 1988.

[57] B. D. Mann, B. M. Eidelsonb, S. G. Fukuchi, S. A. Nissman, S. Robertson, and L. Jardines, "The development of an interactive gamebased tool for learning surgical management algorithms via computer", The American Journal of Surgery 183.3, pp. 305-308, 2002.

[58] B. G. Silverman, J. Holmes, S. Kimmel, C. Branas, D. Ivins, R. Weaver, and Y. Chen, "Modeling emotion and behavior in animated personas to facilitate human behavior change: The case of the HEART-SENSE game", Health Care Manag Sci 4, pp. 213-228, 2001.

[59] A. Kuz, M. Falco, and R. Giandini. "Understanding the teachinglearning environment through Agent SocialMetric." In Information Systems and Technologies (CISTI), 2016 11th Iberian Conference on, pp. 1-4. IEEE, 2016.

[60] H.J. Walberg, and G.J. Anderson, Classroom climate and individual learning. Journal of educational Psychology, 59 (6p1), 414, 1968.

[61] Scott, J., 2012. Social network analysis. Sage.

[62] J. Cassell, Embodied conversational agents. MIT press, 2000.

[63] A. Kuz, M. Falco and R. Giandini, "Student Play: un Módulo Educativo de Agent SocialMetric", In: $4^{\circ}$ Congreso Nacional de Ingeniería Informática / Sistemas de Información (CoNaIISI ‘16). UCASAL. Salta, Argentina, 2016.

[64] L. P. Rieber, "Seriously considering play: designing interactive learning environments based on the blending of microworlds, simulations, and games," Educational Technology Research and Development, vol. 44, no. 2, pp. 43-58, 1996.

[65] M. Prensky, "Digital game-based learning," ACM Computers in Entertainment, vol. 1, no. 1, p. 21, 2003. View at Google Scholar.

[66] J. Powney, M-A. Cullen, U. Schlapp, M. Johnstone, and P. Munn, Understanding value education in the primary school. York: Reports Express. p.vii., 1995.

[67] A. Emilson, and E. Johansson, "Communicated values in teacher and toddler interactions in preschool. In D. Berthelsen, J. Brownlee, \& E. Johansson (Eds.), Participatory learning and the early years: Research and pedagogy (pp. 61-77). New York: Routledge, 2009.

[68] Gobierno de Navarra, (December 12, 2014), Educación diseña una herramienta para medir el grado de desarrollo de los valores del alumnado. Retrieved from https://www.navarra.es/home_es/Actualidad/Sala+de+prensa/Noticias/2 014/12/12/sistema+indicadores+grado+desarrollo+valores+habitos+alu mnado+primaria.htm, (accessed 02.04. 17).

[69] S. de Freitas, M. Ott, eds. New pedagogical approaches in game enhanced learning: Curriculum integration. IGI Global, 2013.

[70] D. Perez-Marin, E. Alfonseca, P. Rodriguez, and I. Pascual-Nieto, "Willow: Automatic and adaptive assessment of students free-text answers", Span. Soc. Nat. Lang. Proc. J, 37, pp. 367-368, 2006.

[71] J. Allen, G. Ferguson, and A. Stent, "An architecture for more realistic conversational systems", Proceedings of the 6th international conference on Intelligent user interfaces, pp. 1-8, ACM, 2001.

[72] J. Lester, K. Branting, and B. Mott, Conversational agents. The Practical Handbook of Internet Computing, pp. 220-240, 2004.

[73] F. Pedro, "New Millennium learners in higher education: Evidence and policy implications." In International Conference on 21st Century Competencies, Brussels: OECD/CERI. 2009.

[74] M. Prensky, "Digital natives, digital immigrants". En The Horizon, 9(5), 2001.

[75] King, L. Stopping Violence in Schools: A guide for Teachers, United Nations: Educational, Scientific and Cultural Organization (2009). 